Conflictual Media Events, Eyewitness Images, and the Boston Marathon Bombing (2013)

Mortensen, Mette

Published in:

Journalism Practice

DOI:

10.1080/17512786.2015.1030140

Publication date:

2015

Document version

Early version, also known as pre-print

Citation for published version (APA):

Mortensen, M. (2015). Conflictual Media Events, Eyewitness Images, and the Boston Marathon Bombing (2013). Journalism Practice, 9(4), 536-551. https://doi.org/10.1080/17512786.2015.1030140 


\section{CONFLICTUAL MEDIA EVENTS, EYEWITNESS IMAGES, AND THE BOSTON MARATHON}

BOMBING (2013)

Mette Mortensen

ABSTRACT: The proliferation of camera phones over the past decade has created an unprecedented landslide of visual information in the online public sphere, transforming the form and amount of communication in relation to crisis events. International research on this subject has primarily centered on the way in which the production and dissemination of eyewitness images convert mainstream media's coverage of crisis. This article broadens the perspective by focusing on eyewitness images in relation to "conflictual media events." The article contributes to discussions on the definition of conflictual media events in today's mediatized and connective media environment, which has undergone radical changes from the era of mass media hegemony when Daniel Dayan and Elihu Katz first outlined media events. The article further examines the ways in which the circulation of eyewitness images erodes established boundaries between experts and laymen and between professionals and non-professionals in relation to conflictual media events. The bombing of the Boston Marathon in April 2013 constitutes the empirical point of departure.

KEYWORDS: Boston Marathon bombing 2013; conflictual media event; experts and laymen; eyewitness images; media event; professionals and non-professionals 


\section{Introduction}

The proliferation of camera phones over the past decade has created an unprecedented landslide of visual information in the online public sphere, transforming the form and amount of communication in relation to crisis events. Traditionally, nations involved in conflict, under attack, or facing natural disasters were prone to manage the population's access to information tightly. In today's digitalized, trans-national, and convergent media landscape, any onlooker or participant constitutes a reporter in the making. International research on this subject has primarily centered on the way in which the production and dissemination of eyewitness images convert mainstream media's coverage of breaking news related to human-caused and (to a lesser extent) natural catastrophes (e.g., Allan 2013, 2014a, 2014b; Andén-Papadopoulos and Pantti 2011, 2013; Chouliaraki 2010; Kristensen and Mortensen 2013, 2014; Mortensen 2011, 2014, 2015; Pantti 2013). This article broadens the perspective by focusing on eyewitness images in relation to "conflictual media events."

The aim of the article is twofold. First, the article contributes to discussions on the definition of media events, which have undergone radical changes since Dayan and Katz (1992) initially outlined this notion during the era of mass media hegemony. Drawing on Hepp and Couldry (2010), this article develops the concept "conflictual media events," i.e., major situations of conflict in today's mediatized and connective media environment. Second, the article also examines the ways in which the circulation of eyewitness images erodes established boundaries between experts and laymen and between professionals and nonprofessionals in relation to conflictual media events.

The bombing of the Boston Marathon in April 2013 constitutes the empirical point of departure. Claimed 
to be "America's first fully interactive national tragedy of the social media age" (Kakutani 2013; see also Allan 2014a, 2014b; Haddow and Haddow 2014), this terror attack exemplifies contemporary conflictual media events and the interplay between citizens, authorities, and the news media prompted by eyewitness images. In the immediate aftermath of the attack, eyewitness images provided the initial visual documentation of the terror attack in the mainstream media, thus fulfilling what has in recent years come to be expected of this genre in situations of breaking news. Citizens were also asked by the authorities to submit their mobile phone images to help the investigation into the course of the event and the identity of the perpetrators. Moreover, users on social network sites collectively scrutinized the mass of available online eyewitness images in order to single out the terrorists in the crowds. The case took another turn when the New York Post newspaper posted a photograph of innocent bystanders on the front page based on the erroneous identification by citizen investigators. A few days later, the Federal Bureau of Investigation (FBI) released the photos of the suspected terrorists, partially out of concern that the criminal investigation could otherwise be hampered by the interplay between citizens and the news media.

The article consists of five sections. Departing from Dayan and Katz' (1992) seminal work, this article begins by engaging in critical discussions on the redefinition of media events to reflect the changing character of both the "media" and "events" in question. This leads to an elaboration on the term conflictual media events, briefly introduced by Hepp and Couldry $(2010,12)$ as "mediatized terror attacks, disaster and war." The second section of the article presents the genre and communicative context of eyewitness images, which are part of the larger ongoing transformation whereby connective culture (van Dijck 2013) alters the representation and communication of conflictual media events. The third section analyzes the way in which the terror attack transformed the Boston Marathon from a celebratory media event in the sense of Dayan and Katz (1992) to a conflictual media event (Hepp and Couldry 2010). Moving one level deeper, the fourth section examines the testing of boundaries between experts and 
laymen as well as between professionals and non-professionals in three different phases of the aftermath of the Boston Marathon bombing. The fifth and final section concludes on the transformation of conflictual media events in today's converging and connective media culture and raises the question of whether the basic distribution of power in media events is affected by these changes.

\section{What Are the Media and What Are the Events of Contemporary Media Events?}

Daniel Dayan and Elihu Katz's pioneering book from 1992, Media Events: The Live Broadcasting of History, defines media events_ or the "high holidays of mass communication"—as pre-planned and ritualized live transmitted events that interrupt the routines of everyday life and are presented with hegemonic "reverence and ceremony" to construct and confirm the unity of the audience (Dayan and Katz 1992, 1, 7, italics in original). Dayan and Katz famously outline three prototypical media events: (1) “conquests" refer to live broadcast of historic achievements transgressing "known limits" "through an act of free will," of which the 1969 moon landing constitutes a paradigmatic example (37); (2) "contests," typically within sports or politics, are distinguished by two or more contending parties striving to win; and (3) "coronations," for instance, state funerals, royal weddings, and (as indicated by the word) coronation ceremonies, place the ceremony essential to all media events in the immediate foreground (37).

The work of Dayan and Katz on the power of television to enthrall and unite audiences was conceived in the era of mass media dominance. Two questions come to mind when considering media events in the current connective and mediatized media landscape distinguished by growing fragmentation and individualization as well as more active roles for the audience: Which events qualify as media events and through which media are they transmitted? Research on this subject has argued for expanding the typology of events. However, scholars have tended to neglect the issue of how today's media events are shaped by "new" online media in conjunction with transformed "old" mass media. This section thus first examines 
the delineation of events in the existing research (primarily Dayan 2010; Dayan and Katz 1992; Katz and Liebes 2007; Liebes 1998; Stepinska 2010) and then departs from Hepp and Couldry (2010) to reflect on the role of converging and connective media_-and their users-in contemporary conflictual media events.

Concerning the type of "events" encompassed in "media events," Dayan and Katz' basic understanding of the integrative function of media events to "celebrate not conflict but reconciliation" has been met with criticism for generating too narrow a selection of media events (Dayan and Katz 1992, 8, italics in original). Arguments have consistently been raised in favor of expanding the concept to include sudden and disruptive events. Similar to traditional media events, disruptive events are transmitted live and become important frames of reference. However, unlike traditional media events, they are not pre- planned by nation states and major organizations or institutions (albeit sometimes by hostile forces). Along these lines, Tamar Liebes raises the following question in her discussion of media events in relation to television "disaster marathons:"

Can such instant, unplanned live broadcast, which interrupt scheduled programmes, gathering the anxious society around the television set, be considered a new sub-genre of media events, or are its characteristics so different that we are witness to a new genre? (Liebes 1998, 72)

Nearly a decade later, Liebes and Katz indirectly offer a positive answer to this question when arguing that, along with celebratory events, "we find disruptive events such as disaster, terror, and war" (Katz and Liebes 2007, 157). Related phrases, such as "negative media events" (Nossek 2008) and "themes that are less tied to celebration and that reflect new tensions in the world," have been brought into play (Dayan 
2010, 24). In particular, terror attacks have been conceptualized as media events in a different sense than the one Dayan and Katz originally assigned to this concept. Similarly to traditional media events, they are distinguished by live broadcast, drama, emotional intensity, narrative predictability, and symbolic value attached to main protagonists, who are, in the case of terror attacks, perpetrators, victims, eyewitnesses, rescue workers, and authorities (Stepinska 2010, 205, see also Dayan 2010; Liebes 1998; Nossek 2008). Terror attacks, however, are obviously distinct from celebratory media events insofar as they lack "contract between three partners: media, audience, and the event organizers, as well as a consensual role of the center (media), providing interpretation and definition of the event," as Agnieszka Stepinska contends (2010, 205-206).

As an important argument for expanding the concept, scholars have placed emphasis on the way in which media events "lend themselves to a rich grammar of appropriations" (Dayan 2010, 30). These appropriations most clearly manifest themselves when integrative or disruptive media events conquer one another and overthrow the original intention and goal. Depending on the chronology of their occurrence, they condition each other in different ways. Integrative events have contributed to healing processes in the wake of disruptive events, e.g., when terror attacks or assassinations on heads of state are followed by memorial ceremonies and public funerals (Hepp and Couldry 2010; Zelizer 1992). Disruptive events, on the other hand, have subverted ceremonial events by means of destructive interventions or accidents. Examples include the terror attack on the 1972 Olympics or the explosion of the space shuttle Challenger after takeoff in 1986. Katz and Liebes $(2007,160)$ accentuate how the inversion from media event to disruptive event is made possible by the fundamental condition of liveness that "something may go wrong" because cameras on site are ready to capture the media event unfolding, whether according to plan—or not. These arguments regarding what Dayan (2010) calls "hijacked" events are highly informative when analyzing the 2013 Boston Marathon bombing, which was transformed from celebration to disruption by 
the terror attack.

Whereas the existing literature on media events has offered critical deliberations on the "event", more reflection could be devoted to the "media." The current article, as already mentioned, subscribes to the concept of "conflictual media event" presented by Andreas Hepp and Nick Couldry in their introduction to the edited volume Media Events in a Global Age (Couldry, Hepp, and Krotz 2010), which studies media events in view of the increasingly heterogenous, decentrered, and globalized media culture. Hepp and Couldry's general definition of media events needs to be discussed before we proceed to their conceptualization of conflictual media events:

[M]edia events are certain situated, thickened, centering performances of mediated communication that are focused on a specific thematic core, cross different media products and reach a wide and diverse multiplicity of audiences and participants. (Hepp and Couldry 2010, 12, italics in original text)

Three specific elements in the above definition deserve closer attention at this point: (1) thematic core of the event, (2) transmission, and (3) reception. Firstly, media events revolve around a thematic core. From the perspective of this article, the thematic core could be specified as the basic character, time, and place of the event as it plays out in the mutually constitutive and dependent spheres of the historical, material world and media representations and communications. Secondly, the transmission crosses "media products" involving various platforms and networks organized either in a "centralized power structure" or "a more multi-centered power structure (as many hope for the Internet)” (Hepp and Couldry 2010, 9). Thirdly, 
media events are received not only by wide audiences (as Dayan and Katz [1992] would have it), but by a "wide and diverse multiplicity of audiences and participants" (cited above)—and, one might add, audiences as participants.

Hepp and Couldry (2010) briefly sketch a typology of media events consisting of "ritual media events," "popular media events," and "conflictual media events", of which the latter is most relevant in the current context. Although they define this category in only a few words, "mediatized terror attacks, disasters or wars" (12), their short definition is still helpful due to its emphasis on "conflictual" (i.e., terror, disaster, and war) and mediatization as basic condition for today's media events. By applying the term mediatization, they indicate that conflictual media events are shaped by the overall development stipulated by mediatization theory (e.g., Hepp 2013; Hjarvard 2013; Lundby 2009, 2014): the media have become integrated into different domains, institutions, and organizations in society, which have adapted their core services, organization, and communication to media logics and technologies; this, in turn, has led to the media developing into separate institutions.

The effects of mediatization on conflictual media events are profound. Strategic and active media use has become essential to crisis communication by authorities addressing citizens directly on social network sites. As a police officer responsible for social media in relation to the Boston Marathon bombing stated, "We don't break news. We are the news" (cited in Haddow and Haddow 2014, 161). Citizens deploy the selfsame social network sites to share, aggregate, and interpret information. Moreover, the expanding number of media and social actors involved in the stream of communication influences the practices of journalism in regard to both the form and content of the mainstream news media's coverage of conflictual media events. News produced by professional journalists crosses platforms and continuously uses or makes references to content published on social network sites often in the form of live presentation of the 
ongoing accumulation of sources and information. Current conflictual media events continue to use television broadcast if not as a mother ship then at least as an indisputably central source of information (Pew Research Center 2013). However, as George D. Haddow and Kim S. Haddow argue in connection with the Boston Marathon bombing, it might be the case that:

[e]ven though television was the most widely-used source of information about the bombing and its aftermath, it was social media that shaped the story and the response. (Haddow and Haddow 2014, 65)

On account of the more diverse, fragmented, and yet connective media in question, media events have become fuzzier in their outline. Determining how, when, and where their production/reception begins and ends has become increasingly difficult. Similarly, the inherent power structures of media events have gained more complexity. This is partly a result of authorities and citizens infiltrating the media in more direct ways. Another reason why the distribution of power has become more opaque is the deployment of diverse media technologies and platforms, facilitated by private organizations with more or less transparent business models and interests. Taking these aspects into account, this article thus refers to conflictual media events as major situations of conflict (terror, armed conflict, disaster) involving both mass media and connective media and drawing the attention of a wide audience, who increasingly contributes actively to the representation and communication of the event.

\section{Eyewitness Images: Genre and Communicative Context}


In this article, eyewitness images are considered as part and symptom of a larger transformation, whereby connective culture (van Dijck 2013) changes conflictual media events. This perspective obviously provides only a partial picture of the complex communicative structures and logics of contemporary conflictual media events, but hopefully general tendencies as well as specific insights into the rapidly growing genre of eyewitness images will emerge.

Eyewitness images first established themselves as a way of communicating conflictual media events during and after the 9/11 terror attack; photographs and videos taken by onlookers contributed vastly to television and online news coverage and later to memorial culture (e.g., Kirshenblatt-Gimblett 2003). In the intervening years, eyewitness images have become a standardized way of depicting sudden and catastrophic events. Examples include natural disasters such as the Indian Ocean tsunami in 2004; Hurricane Katrina in the United States in 2005; the earthquake in Haiti in 2010; and the earthquake in Japan in 2011. Eyewitness images have also documented many man-made crisis situations such as the terror attack in 2005 against the public transport system in London; violent confrontations during civic uprisings (e.g., Burma 2007 and Iran 2009); and the killings of Benazir Bhutto in 2007 and Muammar Gaddafi in 2011. To underpin theoretically the claim of this article that eyewitness images contribute to blurring the boundaries between experts and laymen as well as between professionals and non-professionals, both the genre and communicative context of eyewitness images are taken into consideration in the following.

With respect to genre, eyewitness images are here conceived as either photos or videos taken on location by onlookers, participants, and others not employed by a media institution or organization. In previous writings (Mortensen 2014, 2015), I have outlined five characteristic traits of eyewitness images: autorecordings, subjectivity, participation and documentation, media institutional ambiguity, and decontextualization. These traits might serve as a platform for further analysis into how this genre 
redefines established borderlines by becoming a source both in the news coverage and the criminal investigation. The first characteristic is auto-recordings. Compared to traditional witnessing, testimonies have changed profoundly since the eyewitness is now equipped with a camera and has the option of uploading pictures almost instantaneously. Subjectivity, the second characteristic, manifests itself in the partial and quasi-private point of view. Concerning the third trait, participation and documentation frequently go hand in hand when eyewitness images are taken by somebody performing a professional role or taking active part in other ways. The fourth characteristic, media institutional ambiguity, is the result of the way in which non-professional image producers increasingly operate in semi- professional manners to produce and distribute images targeted at established media institutions. In turn, the news media increasingly welcome and facilitate eyewitness images although they tend to be ambivalent about their legitimacy and validity as sources. Finally, the fifth characteristic, decontextualization, marks both the content and transmission of the material. Information about the producers as well as the depicted individuals, circumstances, locations, etc., is frequently neither volunteered nor easily available through journalistic research. Similarly, the communicative routes and actors behind the information tend to be hard to retrace. Some of these traits are especially important to bear in mind when it comes to the role played by eyewitness images in conflictual media events. Media institutional ambiguity constitutes a basic premise for understanding the way in which images produced by non-professionals enter the professional realm of the mainstream news media and transform the practices of journalism. Subjectivity and decontextualization are decisive for how eyewitness images act as sources in both journalism and criminal investigation.

The communicative context of eyewitness images in relation to conflictual media events is here understood in terms of "connective culture," which according to José van Dijck has replaced "participatory culture:" 
As a result of the interconnection of platforms, a new infrastructure emerged: an ecosystem of connective media with a few large and many small players. The transformation from networked communication to "platformed" sociality, and from a participatory culture to a culture of connectivity, took place in a relatively short time span of ten years. (van Dijck 2013, 4-5)

Eyewitness images circulate in the "online ecosystem," in which tweaks and changes to one part of the system invariably affects other parts of the system (van Dijck 2013, 9), often in unforeseen ways and manners. Moreover, this ecosystem is embedded in "a larger sociocultural and political-economic context where it is inevitably molded by historical circumstances," as van Dijck further contends (9). When conflictual media events take place, eyewitness images are disseminated via existing infrastructures of communication, which are reconfigured in response to the specific situation, the social actors involved, as well as the technological, political, social, and historical contexts.

\section{From Media Event to Conflictual Media Event: The Boston Marathon Bombing (2013)}

The Boston Marathon is the oldest and one of the most prestigious marathons in the world. On April 15, 2013, the terror attack converted the Boston Marathon from a celebratory media event in the sense of Dayan and Katz (1992) to a conflictual media event according to Hepp and Couldry's (2010) definition elaborated on above (see also Mortensen 2015). Two pressure cooker bombs exploded at $2.49 \mathrm{pm}$ near the finish line and killed three bystanders and injured hundreds. Intensive press coverage and police investigation followed, as explained below. On April 18, the FBI released surveillance footage of the 
suspected perpetrators, who were identified later on the same day as the Chechen brothers Dzhokhar and Tamerlan Tsarnaev. This identification triggered a series of dramatic and violent events. The suspects killed a police officer, stole a car, and got into a gunfight with the police. While fleeing from the scene, Tamerlan Tsarnaev, already wounded by gunshots, died after his younger brother ran him over with the car. A largescale manhunt ensued on April 19 to catch Dzhokhar Tsarnaev, who was later found injured in a boat and arrested.

Other research contributions have laid bare the communicative structures of the Boston Marathon bombing with respect to the distribution of roles between professional journalism and citizens engaging in “accidental journalism” (Allan 2014a, 145; see also Allan 2014b) and crisis communication (Haddow and Haddow 2014). In the following, I would like to study the reversal from media event to conflictual media event.

As a long-distance running race, the Boston Marathon belongs to "contests" in Dayan and Katz' typology of media events. Dayan and Katz (1992) explain that contests serve to "accumulate and boast honor through heroic deed and display, to promote unity and collective memory" (28). "Who will win" is the drama inscribed in contests, and these cyclical events proceed according to rituals and formalized rules (34-35). However, the label "contest" is somewhat misleading when applied to marathons, Dayan and Katz maintain, since they mark the sportive accomplishment of "collective protagonists" rather than "individual actors" (49). The audience may identify as much or more with ordinary runners striving to complete the run than with professional athletes aspiring to win. Using the New York City Marathon as an example, Dayan and Katz describe the scene thus: 
The great metropolis is cleared for the run, traffic is interrupted and made to digress, throngs line the streets of the five boroughs, and everybody—as the ABC commentator notes_- "has" somebody who is running: his mailman, her doctor, their priest. (Dayan and Katz 1992, 49)

The race among top runners to cross the finish line first is not the main focus of the bystanders along the route. However, the "communion" transforms into a "contest" once the marathon is experienced via televised transmission, which more clearly stresses the rivalry between elite athletes to win and break new records.

This combination of folk festival and athletic competition adds a vibrant atmosphere to the city, which momentarily replaces the everyday awareness of its lurking dangers with an enchanted view of the urban space as the scene of the marathon:

The spectators are not knowledgeable fans, and the participants are not champions, except for the international start of the "contest" which is superimposed on the folk festival. They all participate in the experience that transforms a dangerous city—Los Angeles, New York, or Paris—into an amiable stadium. They also participate in the interactive experience that permits ordinary spectators to step collectively into a media event, to bask in its aura. Home viewers of these events rediscover their cities. (Dayan and Katz 1992, 207)

The 2013 Boston Marathon bombing puts this quotation in perspective for two reasons. First of all, the city turned into a major crime scene, and the dangers resurfaced in a most ferocious way. As discussed in the theoretical section, this reversal from celebration to disruption is not without precedents. Sporting events have attracted attacks on previous occasions as the combined presence of the media and vast 
numbers of people accommodates the general goal of terrorism of seeking maximum attention by spreading utmost fright and damage to individuals and materials. Besides, according to Dayan and Katz (1992), marathons invite "ordinary spectators" to collectively "bask" in "the aura" of the media event. In 2013, members of the crowd took pictures on a large scale to memorialize and inscribe themselves into the festive narrative of the marathon. Eyewitness images were also important after the reversal of the event, albeit in a different manner. Whereas the snapshots had been part of the documentation of everyday life when the Boston Marathon was still a celebratory media event, they turned into crucial evidence of the conflictual media event. This underscores the point well known from photo theory that the meaning of photographs is context specific (e.g., Sekula 1986; Tagg 1988), which has, of course, only become more momentous as a result of the digital image circuit.

As a conflictual media event, the Boston Marathon bombing was centered around the common core of the sudden terror attack while at the same time being decentered in terms of media platforms and social actors. As Haddow and Haddow explain:

The Boston Marathon bombings were also considered a watershed event; a moment that marked forever the changed role of social media and the fully participatory public in breaking news events and coverage. (Haddow and Haddow 2014, 137)

The news of the terror attack initially broke on Twitter and Facebook, followed 10 minutes after the detonation of the bombs by tweets from The Boston Globe and quickly thereafter the Boston Police Department. Around $4.30 \mathrm{pm}$, a little over an hour and a half after the attack, Twitter included more than 
700,000 mentions of the "Boston Marathon" (Haddow and Haddow 2014, 155). The authorities used social network sites, primarily Twitter, as a tool for crisis communication to update the population about turns of events, correct misinformation, and give safety instructions (Haddow and Haddow 2014). Tweets by the authorities were used in the news coverage, for instance, in live blogs, and runners gave accounts and posted images on Facebook and other social network sites. In other words, this conflictual media event was distinguished by a multitude of intertwined communicative strands, involving primarily mainstream news media and social network sites as well as citizens, authorities, and professional media workers operating with diverse intents and goals.

\section{Experts and Laymen, Professionals and Non-professionals}

This final part of the analysis examines the ways in which the circulation of eyewitness images from the Boston Marathon bombing highlights changes in the conduct of and interplay between citizens, news media, and authorities. The model in Figure 1 offers a more systematic overview of how eyewitness images travel and create meaning in relation to conflictual media events. The model consists of three actors: authorities (government, police, federal bureaus, etc.), media professionals (journalists, editors, etc., employed in a media organization), and citizens (eyewitnesses, participants, users, etc). 


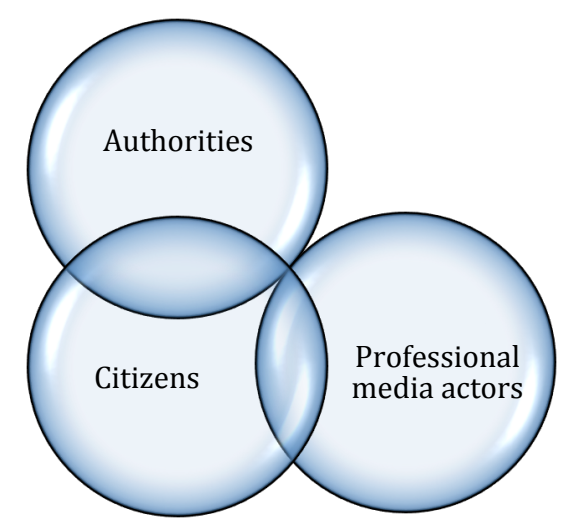

Figure 1: The Circulation of Eyewitness Images in Relation to Conflictual Media Events

The overlapping areas are of particular interest in this analysis because they underscore how eyewitness images enable citizens to move closer to the domains of experts (i.e., criminal investigators, forensic scientists, etc employed by "the authorities") and professional media. ${ }^{1}$ Analytical focus is on eyewitness images in the overlaps between authorities and laymen and between professional media actors and citizens as illustrated in Figure 1. Studying the overlapping areas separately did not make sense, however, as the lines intersected in several places (as indicated by the figure). This is hardly surprising considering how actions in one part of connective culture may spark off counter-actions in other parts. Therefore, this section is structured in accordance with three phases in the aftermath of the Boston Marathon bombing. First, eyewitness images were important to the official investigation. Second, users on social network sites entered into parallel investigation of eyewitness images. Third, the news media deployed not only eyewitness images but also the results of the crowd investigation of eyewitness images in their news coverage, thereby prompting the FBI to release the pictures of the suspected terrorists.

\section{Eyewitness Images as Evidence: Bottom-up Surveillance}

From the outset, the FBI urged citizens to submit images, and public communication by the FBI and other authorities stressed that eyewitness images along with surveillance footage played a major part in the 
reconstruction and investigation of the attack:

"We will go to the ends of the earth to identify the suspect or subjects responsible for this despicable crime," Richard DesLauriers, special agent in charge of the city's FBI office, said at a news conference ... He said citizens can help by sharing images. "There has to be hundreds, if not thousands, of photos and videos," said Timothy Alben, superintendent of the State Police. Boston Police Commissioner Ed Davis said security footage had been taken from nearby businesses. "Even as we were removing victims, officers were assigned to go into the local establishments and secure those videos," he said. (Moroney, Gopal, and Blum 2013)

Spectators and surveillance cameras had thoroughly documented what turned into a crime scene before, during, and after the explosions. The prominence of these two types of visual material reflects parallel developments manifesting themselves expressly in the aftermath of $9 / 11$. Surveillance cameras set up in urban environments on federal or private initiative have increased greatly in numbers, and, as already mentioned, eyewitness images experienced a breakthrough in connection with media coverage of 9/11. Concerning the Boston Marathon, both surveillance and eyewitness footage were recorded on private initiative, but for the distinctly different reasons of protecting businesses against theft and taking snapshots of the sports performance. The FBI collected an estimated one million hours of footage, which "almost became a management problem, there was so much of it" (Montgomery, Horwitz, and Fisher 2013). This material was analyzed both manually and by special software set up to search for people, types or objects, or patterns "such as a certain car that turns up in different places" (CBSNews. com 2013). 
In this context, the bottom-up surveillance system created by the propagation of eyewitness images is particularly interesting. Citizens intentionally or coincidentally capture otherwise hidden or suppressed situations. This tendency not only increases the amount of information available in the public domain but also raises questions pertaining to the protection of privacy as well as the value of the images as proof, given their often subjective, decontextualized, and fragmented character. Surveillance facilitated by eyewitness images obviously has ramifications for other domains. For instance, in civic engagement, activists have become able to document suspected abuse of power by authorities, and in celebrity culture (including politics as an increasingly celebritized field), ever-present citizen paparazzi have reduced the private space of public figures.

\section{Eyewitness Images as Evidence: Crowd Investigation}

Citizens engaged in collective efforts to find the perpetrators by scrutinizing the mass of online eyewitness images created a parallel to the official investigation. The burgeoning snapshot culture generated images of relevance to the authorities, which were also made available in the online public sphere. Digital accessibility of empirical data and knowledge along with networked communication and crowd sourcing constitute the spine of what has alternatively been termed "crowd science," "networked science," "public science," or “crowd-sourced science.” Alexander Halavais comments on this emerging field (see also Mortensen 2015):

Non-academics have long done social and behavioral research, just as non-journalists created news long before and after the professionalization of journalism. In both cases, networked communication makes it relatedly easier for non-professionals to engage on their own time and in their own ways, finding communities of likeminded individuals. The resources available to 
today's amateur are different not just in scale but in type from those available in previous decades. (Halavais 2013)

Eyewitness images make provision for the "people formerly known as the audience" to enter traditional domains of experts. In the case of the Boston Marathon bombing, they knock on the door of forensic science and criminology with a collective investigation into clues about the identities of the terrorists in the masses of available online eyewitness images.

Receiving most attention, the so-called subreddit "findbostonbombers" on Reddit was named "the flagship site for the unofficial investigation" (Fahrenthold and Dewey 2013). A few quotations from the anonymous moderator of this subreddit in the Washington Post might give an idea of why this venue was considered controversial:

"Find people carrying black bags," wrote the Reddit forum’s unnamed moderator. "If they look suspicious, then post them. Then people will try and follow their movements using all the images."

The moderator defended this strategy by arguing that “it's been proven that a crowd of thousands can do things like this much quicker and better ... I'd take thousands of people over a select few very smart investigators any day.” (Montgomery, Horwitz, and Fisher 2013)

The statements by the subreddit moderator seem to imply that terrorists "look suspicious," i.e., have certain appearances and exhibit specific forms of behavior, perceptible and recognizable even to the 
untrained eye. Moreover, the moderator argues that "thousands of people" may accomplish more than "a few very smart investigators," despite public opinion having deemed these laymen investigators to be ““online vigilantes,' 'digital witch-hunt[er]s,' and 'conspiracy nuts”' (cited in Allan 2014a, 136).

After the controversy, Reddit closed the subreddit "findbostonbombers." A similar and still existing online forum is "4chan ThinkTank" on the social network site Imgur. This site might give an impression of how users searched eyewitness images and other publicly available footage by drawing comparisons between the images to track alleged suspicious movement and behavior. ${ }^{2}$ Two of the men singled out by this investigation as "suspect \#1" and "suspect \#2" are identical to the individuals posted on the front page of the New York Post, to which we shall shortly return. These acts of (mis)identification draw on two established approaches to identity and identification, as I have explained at more length elsewhere (Mortensen 2015). First, photography has been used since the nineteenth century as a means of identifying the individual and fixing his or her visual identity in a singular and stable manner. Second, the other tradition brought into play by this site was the collective management and construction of identity on social media, e.g., when individuals put on display, or have put on display by others, a desired and designed image of the self, or when they are publicly denounced as offenders.

While visual evidence used to be protected and kept strictly within the institutions responsible for surveillance and criminal investigation, it is becoming more easily available online whether disseminated on publicly accessibly sites or by leaks as a "standard feature for information exchange" (Trottier and Lyon 2012, 101). These collections of data allow citizens to look the authorities over the shoulder, so to speak, and conduct alternative reconnaissance. 


\section{Eyewitness Images Making the Front Pages and the FBI Reclaiming Authority}

As the most obvious manifestation of the field in-between professionals and non- professionals, the Boston Marathon bombing confirmed how eyewitness images have become a standard resource for the established news media in the coverage of topical events. They were deployed extensively in the news but

gained most attention when the New York Post, under the headline "Bag Men," posted an amateur picture on the front page of the two young men incriminated on Reddit, Imgur, and other social network sites. In other words, the paper used images by citizens on the lead of citizens. A somewhat paradoxical point raised in this regard is that the news media's deployment of images taken by citizens could be interpreted as an attempt to compete with, precisely, citizens. As Stuart Allan (2014a, 136) remarks, "news organisations were striving to compete with their citizen media rivals to be first with a 'scoop."' This use of eyewitness images underscores points brought forward in existing research on the opportunities and challenges arising from the news media's increasing circulation of this genre (e.g., Allan 2013; Andén-Papadopoulos and Pantti 2011, 2013; Chouliaraki 2010; Kristensen and Mortensen 2013, 2014; Mortensen 2011, 2014, 2015; Pantti 2013). Eyewitness images have created an unprecedented access to information by allowing more people to partake in conflict and crisis reporting, thus challenging the news media's traditional monopoly on creating news content as well as strategic communication by the authorities. Also, the Boston Marathon bombing revitalized questions concerning the veracity and reliability of the sources as well as the fragmentation and decontextualization of information, all of which put professional norms and standards of journalism to the test (see also Allan 2014a, 2014b).

When the FBI released surveillance stills and videos of the two suspects on April 18, three days after the attack, it was partially in response to the New York Post posting eyewitness photos of innocent bystanders on the front page. The decision to publicize the photos was at least in part motivated by concern that the 
criminal investigation might otherwise be harmed by citizens performing detective work on the eyewitness images, and the news media using their results as sources:

Investigators didn't want to risk having news outlets put out the Tsarnaevs' images first, which might have made them the object of a wave of popular sympathy for wrongly suspected people, as had happened with two high school runners from the Boston area whose photos were published on the front page of the New York Post under the headline "Bag Men."

...Investigators were concerned that if they didn't assert control over the release of the Tsarnaevs' photos, their manhunt would become a chaotic free-for-all, with news media cars and helicopters, as well as online vigilante detectives, competing with police in the chase to find the suspects. By stressing that all information had to flow to 911 and official investigators, the FBI hoped to cut off that freelance sleuthing and attend to public safety even as they searched for the brothers. (Montgomery, Horwitz, and Fisher 2013)

Several elements are worthy of note in the deliberations of the FBI on the release of the visuals. To begin with, the New York Post's wrongful exposure of innocent bystanders as the suspects had weakened the trust in the news media. Therefore, it could be interpreted as another cry wolf if the news media were the first to publish the images of the actual terrorists. The FBI had to assert its authority to issue the images, which the public should trust and pay attention to. As the FBI agent in charge of the investigation, Richard DesLauriers stresses in another article, "the only official photos, which should be officially relied upon, are those you see today" (Fahrenthold and Dewey 2013). Although the FBI had profited from the involvement 
of citizens during the initial stages, the possible damage exerted on the investigation by the interplay between media and citizens now became a major consideration in the conduct and communication of the search for the terrorists. For this reason, the FBI redrew the line between experts and laymen and between professionals and non-professionals after the muddling of these spheres in the earlier stages of the conflictual media event had resulted in a "chaotic free-for-all," to borrow the words from the quote above.

\section{Conclusion}

This article has centered on the changing nature of conflictual media events and the different ways in which eyewitness images contribute to the interplay between authorities, citizens, and the news media. Media events have traditionally involved close cooperation between the news media and the authorities. However, the infiltration of eyewitness images on several levels is symptomatic of the emerging impact of citizens not only on media representations but also on the shaping of conflictual media events.

The aim of this article has been to widen the perspective on eyewitness images by examining the dissemination and applied functions of this genre as part of the connective and extended circuit of information making up contemporary conflictual media events. Due to the intensified and concentrated media supply and consumption, media events might figuratively speaking work as magnifying glasses. Tendencies in the current media environment are enlarged and brought together, in this case to emphasize how citizens interact with and interfere in the realms of professional media and authorities by the production, distribution, and crowd sourcing of images. This also means that the Boston Marathon bombing, on account of the considerable attention directed to this terror attack on US soil, constitutes a more extreme case for studying the blurred borderlines between experts and laymen and professionals and non-professionals than would be, for instance, media coverage of minor criminal incidents. 
The analysis revealed several indications of what was referred to in the theoretical section as the fuzzier outline of contemporary media events. Acts of communication in relation to conflictual media events often serve various purposes. Along with the multiple functions of eyewitness images, one could also bring forward as an example the crisis communication by the authorities, primarily on Twitter, which fed the news media and entered into citizens' private exchanges on social network sites. Another manifestation of the fuzzy outline is that, by comparison to earlier media events, the Boston Marathon bombing did not appear to contain an iconic image. As pointed out by, Marriott (2001) and Mortensen (2015), media events have been distinguished by a particular "moment" or "instant or instants" (Marriott 2001, 725) that can be seized upon as iconic and reproduced over and over again in the news and popular culture. For example, $9 / 11$ is remembered by a handful of images, including the ones of the hijacked planes heading toward the World Trade Center towers; the civic uprising in Burma 2007 is remembered by images of monks taking to the streets of Rangoon; and the civic uprising in Iran 2009 by the footage of the killing of a woman, Neda Agha Soltan. One may speculate that the sheer quantity of eyewitness images and the fact that the events were not exclusively broadcast on television could have contributed to this; there is no empirical evidence to support this at present, however.

A final conclusion concerns the drawing of the lines between experts and laypeople and between professionals and non-professionals. One pertinent question in this regard is whether the involvement of citizens de facto alters the distribution of power in relation to conflictual media events, which have been characterized by tight top-down management and orchestrations from governments, media organizations, as well as other institutions and organizations. The deployment of bottom-up communicative forms, such as eyewitness images, by the authorities does not necessarily change basic power relations, just as the involvement of citizens may serve purposes beyond their own immediate interests. While this study has centered on the various investments and interests in eyewitness images during the course of a conflictual 
media event, future research on interactions and negotiations between diverse actors and organizations would shed light on this pertinent question of the division of power.

\section{DISCLOSURE STATEMENT}

No potential conflict of interest was reported by the author.

\section{NOTES}

1. They do not overlap in the case of authorities and professional media actors because there is no considerable circulation of eyewitness images between the two.

2. See http://imgur.com/a/sUrnA.

\section{REFERENCES}

Allan, Stuart. 2013. Citizen Witnessing: Revisioning Journalism in Times of Crisis. Key Concepts in Journalism. Cambridge: Polity Press.

Allan, Stuart. 2014a. "Witnessing in Crisis: Photo-reportage of Terror Attacks in Boston and London." Media, War \& Conflict 7 (2): 133-151. doi:10.1177/1750635214531110.

Allan, Stuart. 2014b. "Reformulating Photojournalism: Interweaving Professional and Citizen PhotoReportage of the Boston Bombings.” In Citizen Journalism. Global Perspectives, edited by Stuart Allan and Einar Thorsen, 155-169. New York: Peter Lang.

Andén-Papadopoulos, Kari, and Mervi Pantti. 2011. Amateur Images and Global News. Chicago: 
University of Chicago Press.

Andén-Papadopoulos, Kari, and Mervi Pantti. 2013. "Re-imagining Crisis Reporting: Professional Ideology of Journalists and Citizen Eyewitness Images.” Journalism. Theory, Practice and Criticism 14 (7): 960-977. doi:10.1177/1464884913479055.

CBSNEWS.com. 2013. “FBI Release Video of 2 Boston Bombing Suspects.” April 18.

Chouliaraki, Lilie. 2010. “Ordinary Witnessing in Post-television News: Towards a New Moral Imagination.” Critical Discourse Studies 7 (4): 305-319.

Couldry, Nick, Andreas Hepp, and Friedrich Krotz. 2010. Media Events in a Global Age. Comedia. London: Routledge.

Dayan, Daniel. 2010. “Beyond Media Events: Disenchantment, Derailment, Disruption.” In Media Events in a Global Age, edited by Nick Couldry, Andreas Hepp, and Friedrich Krotz, 23-31. New York: Routledge.

Dayan, Daniel, and Elihu Katz. 1992. Media Events: The Live Broadcasting of History. Cambridge, MA: Harvard University Press.

Fahrenthold, David A., and Caitlin Dewey. 2013. "Backpack Brothers and Example of the Drawbacks to Internet Sleuthing.” Washington Post, April 19.

Haddow, George D., and Kim S. Haddow, 2014. Disaster Communications in a Changing Media World. 2nd ed. Amsterdam: Elsevier B.V.

Halavais, Alexander. 2013. "Home Made Big Data? Challenges and Opportunities for Participatory Social 
Research.” First Monday 18 (10). doi:10.5210/fm.v18i10.4876.

Hepp, Andreas. 2013. Cultures of Mediatization. Cambridge: Polity. Hepp, Andreas, and Nick Couldry. 2010. "Introduction: Media Events in Globalized Media

Cultures.” In Media Events in a Global Age, edited by Nick Couldry, Andreas Hepp, and

Friedrich Krotz, 1-20. New York: Routledge. Hjarvard, Stig. 2013. The Mediatization of Society and Culture. New York: Routledge. Kakutani, Michiko. 2013. 'Unraveling Boston Suspects’ Online Lives, Link by Link." The New York

Times, April 23. Katz, Elihu, and Tamar Liebes. 2007. “No More Peace!’: How Disaster, Terror and War Have

Upstaged Media Events.” International Journal of Communication 1: 157-166. Kirshenblatt-Gimblett, B. 2003. "Kodak Moments, Flashbulb Memories: Reflections on 9/11."

TDR/The Drama Review 47 (1): 11-48. doi:10.1162/105420403321249983. Kristensen, Nete Nørgaard, and Mette Mortensen. 2013. “Amateur Sources Breaking the News, Metasources Authorizing the News of Gaddafi's Death. New Patterns of Journalistic Information Gathering and Dissemination in the Digital Age.” Digital Journalism 1 (3):

352-367. doi:10.1080/21670811.2013.790610. Kristensen, Nete Nørgaard, and Mette Mortensen. 2014. "Non-professional Visuals Framing the

News Coverage of the Death of Muammar Gaddafi.” In Mediating and Remediating Death, edited by Dorthe Refslund Christensen and Sandvik Sandvik, 133-154. Farnham: Ashgate. Liebes, Tamar. 
1998. “Television’s Disaster Marathons. A Danger for Democratic Processes?” In Media,

Ritual and Identity, edited by Tamar Liebes and James Curran, 71-84. London: Routledge. Lundby, Knut. 2009. Mediatization: Concept, Changes, Consequences. New York: Peter Lang. Lundby, Knut. 2014. Mediatization of Communication. Handbooks of Communication Science.

Berlin: De Gruyter Mouton. Marriott, Stephanie. 2001. "In Pursuit of the Ineffable: How Television Found the Eclipse but Lost

the Plot.” Media, Culture \& Society 23 (6): 725-742. doi:10.1177/016344301023006003. Montgomery, David, Sari Horwitz, and Marc Fisher. 2013. "Police, Citizens and Technology

Factor into Boston Bombing Probe." The Washington Post, April 21. Moroney, Tom, Prashant Gopal, and Justin Blum. 2013. "FBI Asks for Spectator Video of Boston

Marathon Bombing.” Bloomberg, April 16. Mortensen, Mette. 2011. “When Citizen Photojournalism Sets the News Agenda: Neda Agha

Soltan as a Web 2.0 Icon of Post-election Unrest in Iran.” Global Media and Communication 7 (1): 4-16. doi:10.1177/1742766510397936.

Mortensen, Mette. 2014. “Eyewitness Images as a Genre of Crisis Reporting.” In Citizen Journalism: Global Perspectives, Vol. 2, edited by Stuart Allan and Einar Thorsen, 143-154. New York: Peter Lang.

Mortensen, Mette. 2015. Eyewitness Images. Digital Media, Participation, and Conflict. New York: Routledge.

Nossek, Hillel. 2008. “News Media’ - Media Events: Terrorist Acts as Media Events.” Communications: 
The European Journal of Communication Research 33 (3): 313-330.

Pantti, Mervi. 2013. “Getting Closer? Encounters of the National Media with Global Images.” Journalism Studies 14 (2): 201-218. doi:10.1080/1461670X.2012.718551.

Pew Research Center. 2013. Six-in-Ten Say Post 9/11 Steps Have Made Country Safer, Accessed April 6, 2015. http://www.people-press.org/files/legacy-pdf/4-23-13\%20Boston\%20Release.pdf.

Sekula, Allan. 1986. “The Body and the Archive.” October 39 (Winter): 3-64. Stepinska, Agnieszka 2010. “9/11 and the Transformation of Globalized Media events." In Media Events in a Global Age, edited by Nick Couldry, Andreas Hepp, and Friedrich Krotz, 203-

216. London: Routledge. Tagg, John. 1988. The Burden of Representation: Essays on Photographies and Histories. Amherst:

University of Massachusetts Press. Trottier, Daniel, and David Lyon. 2012. "Key Features of Social Media Surveillance.” In Internet and

Surviellance: The Challenges of Web 2.0 and Social Media, edited by Christian Fuchs, Kees

Boersma, Anders Albrechtslund, and Marisol Sandoval, 89-105. New York: Routledge. van Dijck, José. 2013. The Culture of Connectivity: A Critical History of Social Media. Oxford: Oxford

University Press. Zelizer, Barbie. 1992. Covering the Body: The Kennedy Assassination, the Media, and the Shaping

of Collective Memory. Chicago: University of Chicago Press. 


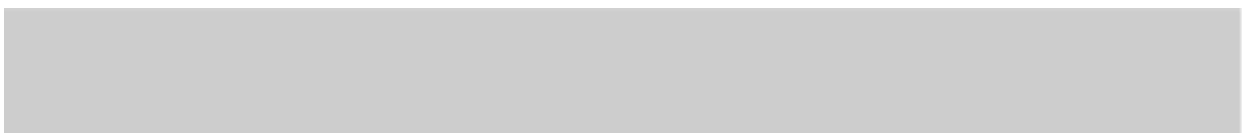

Mette Mortensen, Department of Media, Cognition and Communication at the University of Copenhagen,

Denmark.E-mail: metmort@hum.ku.dk 